\title{
Perfil Clínico Da Leptospirose Em Santa Cruz Do Sul (RS): Revisão Dos Anos De 2012 E 2013
}

\author{
Pereira, B.F.; Bassani, D.C.H.; Chaves, J.; Tabile, P.M.; Krummenauer, E.C.; \\ Carneiro, M.;
}

Apresentador: Bruna Fernandes Pereira

\section{Resumo}

Introdução: a leptospirose é uma zoonose de distribuição universal, sendo causada por uma bactéria do tipo Leptospira, cuja transmissão ocorre pelo contato com urina de animais infectados ou água e lama contaminada. É uma doença infecciosa febril de início abrupto, cujo espectro clínico pode variar desde quadros oligossintomáticos de evolução benigna a quadros graves. Dentre os sintomas mais prevalentes estão cefaleia, mialgia e prostração. O objetivo do estudo é analisar o perfil do paciente com leptospirose atendido em Santa Cruz do Sul (RS). Método: estudo descritivo, de abordagem quantitativa, realizado através da análise das fichas de notificação compulsória do Sistema de Informação de Agravos de Notificação dos casos confirmados de leptospirose atendidos em Santa Cruz do Sul-RS, no período de janeiro de 2012 a dezembro de 2013. Resultados: em 2012 foram confirmados 26 casos no município, sendo 20 (76,92\%) do sexo masculino. Já em 2013, houve 30 casos, com 27 (90\%) homens acometidos. Ao se analisar ambos os anos, a média de idade foi de 42,73 anos, variando de 7 a 77. Nenhuma gestante foi acometida no período analisado. Com relação à procedência, em 2013 a maioria $(56,66 \%)$ era da zona urbana, e em 2012, os valores das zonas rural e urbana se equivaleram. Na análise da situação de risco, as opções "rio, córrego, lagoa ou represa" e "terreno baldio" foram predominantes em 2012: $57,69 \%$ e $69,23 \%$, respectivamente. Já “criação de animais" preponderou em ambos os anos: 2012, $92,30 \%$ e em $2013,80 \%$. Os sinais e sintomas prevalentes foram febre, com 24 (92,30\%) casos em 2012 e $30(100 \%)$ no ano posterior mialgia, $25(96,15 \%)$ e $28(93,33 \%)$, respectivamente no período do estudo dor na panturrilha, $19(73,07 \%)$ e $22(73,33 \%)$ cefaleia, $22(84,61 \%)$ e $28(93,33 \%)$ e prostração, com $23(88,46 \%)$ e $25(83,33 \%)$. A hospitalização ocorreu em $24(92,30 \%)$ casos em 2012 e $25(83,33 \%)$ em 2013. O tempo de internação médio foi de 4,22 dias, variando de zero a 17 dias. Conclusões: o perfil de pacientes com leptospirose no estudo concentrou-se em adultos, a maioria do sexo masculino, sendo a procedência, em relação à zona urbana e rural, quase equivalente em 2013 e equivalente em 2012 com relação à situação de risco, houve predomínio "do contato com animais" os sinais e sintomas mais prevalentes foram febre, mialgia, cefaleia, dor na panturrilha e prostração observou-se alto número de hospitalizações, sugerindo um grave espectro da doença na localidade.

\section{Referência:}

Pereira, B.F.; Bassani, D.C.H.; Chaves, J.; Tabile, P.M.; Krummenauer, E.C.; Carneiro, M.;. Perfil Clínico Da Leptospirose Em Santa Cruz Do Sul (RS): Revisão Dos Anos De 2012 E 2013. In: II Congresso Brasileiro de Medicina Hospitalar - II CBMH [= Blucher Medical Proceedings, vol.1, num.5] São Paulo: Editora Blucher, 2014. p.39

DOI 10.5151/medpro-II-cbmh-032 